\title{
Patients' experience of dangerous and severe personality disorder services: qualitative interview study
}

\author{
Julia Sinclair, Lucy Willmott, Ray Fitzpatrick, Tom Burns, Jenny Yiend and the IDEA Group
}

\begin{abstract}
Summary
As part of an evaluation of the Dangerous and Severe Personality Disorder (DSPD) Programme, we conducted in-depth interviews with 60 participants purposely sampled across four pilot DSPD units. This report is limited to the finding with potential 'conceptual generalisability': namely the unanticipated finding of negative and hostile attitudes of participants being managed in hospital units compared
\end{abstract}

with the prison system. The recent UK government policy decision to concentrate this programme in prisons may, in part, reflect the significance of these findings.

\section{Declaration of interest}

None.
Dangerous and severe personality disorder (DSPD) is an administrative category, not a medical diagnosis, and whether individuals so labelled should be managed within high secure hospitals or prisons remains a subject for debate. A pilot study of four sites in the UK (two within high-security hospitals and two within the prison system) is complete and although the UK Dangerous and Severe Personality Disorder Programme is being scaled down, there is a need to learn lessons for the future management of this difficult group. ${ }^{1}$

\section{Method}

The DSPD Programme and the baseline characteristics of participants involved in the Inclusion for DSPD Evaluating Assessment and treatment (IDEA) study are described elsewhere. ${ }^{2,3}$ The aim of this short report is to describe the experiences and responses of participants to the treatment pathway and environment of the DSPD units.

An interview topic guide was developed and piloted, designed to identify aspects of services that are perceived as either facilitating or inhibiting participant progress. Participants were purposely sampled from the four DPSD sites described above according to time on the unit and individual wing/ward. ${ }^{4}$ Secondary sampling characteristics (e.g. age, IQ score, personality indicators, offence history) were collected to investigate characteristics across the whole sample. ${ }^{5}$

Interviews, lasting on average $40 \mathrm{~min}$, were conducted by one research assistant at each site. Participants were reassured about the confidentiality of interviews (unless they disclosed material indicating imminent serious harm or escape), and were encouraged to discuss topics of greatest relevance to them. All interviews were recorded, transcribed, checked and imported into NVivo software on Windows XP. ${ }^{6}$ A form of framework analysis was undertaken to systematically analyse the data. ${ }^{7,8}$

\section{Results}

Sixty men were interviewed. They did not differ significantly from the overall sample $(n=168)$ on any baseline characteristics (online Table DS1), specifically referring location, index offence and clinical characteristics. ${ }^{1}$ Men in the prison units retained the status of 'prisoner', whereas those in hospital had the same rights as other people detained under the Mental Health Act in a secure facility.

\section{Perception of the use of time}

The majority of participants talked of waiting for time to pass or for something to occupy them (online supplement 1). Although the individual timetables of participants in the study showed that those in prison spent a greater proportion of time in lock-up, ${ }^{2}$ hospital participants disproportionately talked of 'waiting' as a major factor, and had far greater expectations that their time would be spent in therapies or structured activities. The impact of time spent waiting to be occupied was essentially a negative one. The main associated emotional states described were boredom, frustration and an exacerbation of negative mood states (particularly feelings of depression and anxiety). Several participants specifically mentioned the link between 'waiting' and their feelings of becoming 'wound up', making threats of violence (to themselves or others) or being verbally aggressive.

The descriptions of acting out and other emotional responses to believing that so much time was wasted were not, however, associated with particular participant characteristics such as the number or type of personality disorders, or the participant's IQ score. Rather, it appeared to be related to the degree of waiting that an individual perceived relative to his desire to be occupied, or his sense of entitlement to engage in therapy. Although overall the hospital units were described as providing the widest range of activities in well-equipped, purpose-built facilities, the participants in these units were much more likely than those in the prison system to complain that they spent excessive time waiting to attend such activities.

\section{Patient or prisoner status}

More participants in hospital (44\%) than in prison units $(7 \%)$ talked of how they considered aspects of procedural security as curtailing their autonomy and restricting access to activities. The initial procedures following admission were perceived as punitive by some of those within the hospital system relative to equivalent prison procedures. They saw the loss of privileges and curtailment of activities arising from procedural security as difficult to understand or justify. These included not being allowed their own razor, a two-person escort, no personal items allowed in their room, being secluded for swearing, and being 
subjected to rub-downs, being stripped and showered. Thirteen participants ( 12 in the hospital system) described these procedures as engendering feelings of annoyance and frustration through to resentment, hate and alienation. There were associations between how the participant had come to the unit and his emotional response to it, particularly in relation to unmet expectations. Participants who perceived themselves as having little choice or warning of coming to the programme (whether they did or not) formed the largest group in the sample and were unequally divided between the hospital and prison systems, potentially reflecting the different legal mechanisms for detention, but also their perception of the purpose in being transferred.

One hospital participant talked of being made to feel 'back straight into the frame of mind of being a prisoner'. None of the prison sample considered the regime in these terms, indeed several described it in terms of being 'safe', 'friendly' and 'relaxing'. Participants within the prison system, although critical of aspects of the regime, seemed more willing to accept that as a prisoner there was a reason why they were incarcerated, other than simply as a waiting area for therapy. All the participants met the criteria for DSPD (severe personality disorder, directly linked to a high risk of further serious offending), yet those managed within the hospital system were more focused on their entitlement to treatment than their role as offender.

\section{Discussion}

There appeared to be a substantial and unanticipated difference between the participants in the prison and hospital groups in how they perceived their identity on the units, not accounted for by individual differences. Results from the wider study showed that transfer into the DSPD Programme resulted in considerable uncertainty about progressing through the system in both prison and hospital units, ${ }^{2,3}$ but from the participants' perspective there was something specific to the hospital units that made this less acceptable. Overall, the narrative of participants in hospital reflected an adoption of the sick role, with an entitlement to treatment. Participants in the prison units, in general, appeared much less demanding of the system. They saw themselves with fewer entitlements or less ability to affect their ultimate outcome. This requires further exploration in future studies of DSPD populations and those managed in other personality disorder services.

This study indicates the importance of using qualitative methods when evaluating novel treatments and policies," highlighting possible unintended consequences that would not be accessible to study by quantitative observational or randomised trials alone. The use of several methods of inquiry allows for triangulation of the results, which strengthens the qualitative findings. ${ }^{2}$ Strengths of this study include the use of a large, broadly representative sample such that the findings are unlikely to be due to sampling bias of a particularly difficult group (e.g. those transferred to hospital at the end of their sentence) Limitations include the inherent differences in terms of legal status between the prison and hospital groups, and identifying differences between the two groups may be a proxy for this.
How participants describe their experiences suggests that the setting in which they are treated has a profound effect on their attitude, a potentially significant implication for their management.

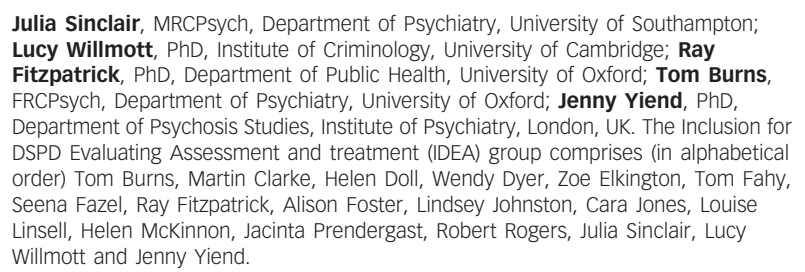

Julia Sinclair, MRCPsych, Department of Psychiatry, University of Southampton; Lucy Willmott, PhD, Institute of Criminology, University of Cambridge; Ray Fitzpatrick, PhD, Department of Public Health, University of Oxford; Tom Burns, FRCPsych, Department of Psychiatry, University of Oxford; Jenny Yiend, PhD, Department of Psychosis Studies, Institute of Psychiatry, London, UK. The Inclusion for DSPD Evaluating Assessment and treatment (IDEA) group comprises (in alphabetical order) Tom Burns, Martin Clarke, Helen Doll, Wendy Dyer, Zoe Elkington, Tom Fahy, Seena Fazel, Ray Fitzpatrick, Alison Foster, Lindsey Johnston, Cara Jones, Louise Linsell, Helen McKinnon, Jacinta Prendergast, Robert Rogers, Julia Sinclair, Lucy Willmott and Jenny Yiend.

Correspondence: Dr Julia Sinclair, Department of Psychiatry, University of Southampton, Academic Centre, College Keep, 4-12 Terminus Terrace, Southampton S014 3DT, UK. Email: julia.sinclair@soton.ac.uk

First received 23 Aug 2011, final revision 2 Dec 2011, accepted 19 Dec 2011

\section{Funding}

The study was funded by the UK Ministry of Justice and Department of Health through the Dangerous and Severe Personality Disorder Programme.

\section{Acknowledgements}

We thank the Dangerous and Severe Personality Disorder Expert Advisory Group for comments on the report manuscript. We are also deeply indebted to the clinical staff at each of the four sites, led by Professor Tony Maden, Julie Luther, Lawrence Jones, Dr Gopi Krishnan and Dr Jacqui Saradjian. Conducting research in such high secure settings places significant burdens on all involved and we were received with cooperation and generosity. The opinions expressed in this paper are those of the authors and not necessarily those of the Ministry of Justice.

\section{References}

1 Duggan C. Dangerous and severe personality disorder. Br J Psychiatry 2011; 198: $431-3$.

2 Burns $\mathrm{T}$, Yiend J, Fahy T, Fitzpatrick R, Rogers R, Fazel S, et al. Treatments for dangerous severe personality disorder (DSPD). J Forens Psychiatry Psychol 2011; 22: 411-26.

3 Burns T. Dangerous severe personality disordered (DSPD) patients: characteristics and comparison with other high-risk offenders. Int J Forens Mental Health 2011; 10: 127-36.

4 Murphy $E$, Dingwall $R$, Greatbatch $D$, Parker $S$, Watson $P$, Qualitative research methods in health technology assessment: a review of the literature. Health Technol Assess 1998; 2: iii-274.

5 Hammersley M. The generalisability of ethnography. In What's Wrong With Ethnography? (ed. M Hammersley): 85-95. Routledge, 1992.

6 QSR International. Nvivo 8 Qualitative Data Analysis Software. QSR International, 2008.

7 Ritchie J, Lewis J. Qualitative Research Practice: A Guide for Social Science Students and Researchers. Sage, 2003.

8 Ritchie J, Spencer L. Qualitative data analysis for applied policy research. In Analysing Qualitative Data (eds A Bryman, RG Burgess): 173-94. Routledge, 1994

9 Campbell M, Fitzpatrick R, Haines A, Kinmonth AL, Sandercock $P$, Spiegelhalter $D$, et al. Framework for design and evaluation of complex interventions to improve health. BMJ 2000; 321: 694-6. 